\title{
ОБ ОЦЕНКЕ УРОВНЯ ИННОВАЦИОННОЙ ДЕЯТЕЛЬНОСТИ ПОДРАЗДЕЛЕНИЙ ВЫСШЕГО УЧЕБНОГО ЗАВЕДЕНИЯ В УСЛОВИЯХ ДИСТАНЦИОННОГО ОБУЧЕНИЯ
}

\author{
(C) 2020 Агибалова Елена Леонидовна \\ кандидат филологических наук, доцент, заведующая кафедрой иностранных языков № 3 \\ Российский экономический университет им. Г. В. Плеханова, Россия, Москва \\ E-mail: kafedra-iy3@rea.ru
}

\section{(c) 2020 Каржанова Наталья Викторовна}

кандидат филологических наук, доцент, кафедра иностранных языков № 3

Российский экономический университет им. Г. В. Плеханова, Россия, Москва

E-mail: Karzhanova.NV@rea.ru

(c) 2020 Копылова Елена Викторовна

кандидат филологических наук, доцент, кафедра иностранных языков № 3

Российский экономический университет им. Г. В. Плеханова, Россия, Москва

E-mail: Kopylova.EV@rea.ru

(c) 2020 Марциновская Виктория Александровна

старший преподаватель, кафедра иностранных языков № 3

Российский экономический университет им. Г. В. Плеханова, Россия, Москва

E-mail: vitam1981@mail.ru

В статье авторов рассматривается вопрос оценки уровня инновационной деятельности подразделений высшего учебного заведения в условиях дистанционного обучения. Объектом исследования выступили подразделения высшего учебного заведения. Предметом же - уровень их инновационной деятельности в условиях дистанционного обучения. Теоретическое и методологическое значение исследования заключены в расширении теории и методологии управления инновационной деятельностью в сфере образования. Практическое значение исследования заключено в модернизации применения подходов к оценке уровня инновационной деятельности субъектов.

Ключевые слова: Оценка, уровень, инновационная деятельность, подразделение, высшее учебное заведение, условие, дистанционное обучение.

Сложности текущего периода, определенные мировым кризисом распространения коронавирусной инфекции, вынудили практически все без исключения хозяйствующие субъекты (от крупного бизнеса до сферы образования) применить комплексные меры защиты, включающие, в том числе инструментарий социального дистанцирования [5, с. 55]. Указанные действия в совокупности позволили, некоторым образом, сдержать распространение опасного заболевания в первых трех кварталах 2020 года и определили будущий вектор развития безопасных социальных коммуникаций [6] на всей планете Земля.

Институт социального дистанцирования в середине 2020 года, по данным ряда крупнейших консалтинговых и исследовательских компаний $[6,7]$, наиболее выражено во всем мире нашел свое применение в таких сферах человеческой деятельности как производство, образование и услуги (рис. 1). Ведь именно здесь имеют место наиболее тесные контакты между субъектами в процессе выполнения ими своих должностных обязанностей.

Для снижения риска передачи новой инфекции в 2020 году значения параметров, приведенных на рисунке 1 , по оценкам специалистов должны быть снижены в среднем не менее, чем в 3,9 раза. А для этого институт социального дистанцирования должен активно и эффективно применяться не менее, чем в 96,89 процентах субъектов Российской Федерации.

На практике же, ввиду воздействия тех или иных причин, имеют место некоторые значительные отклонения от обозначенной нормы. Так, например, в сфере высшего образования в Российской Федерации [6] во втором и третьем кварталах 2020 года институт социального 


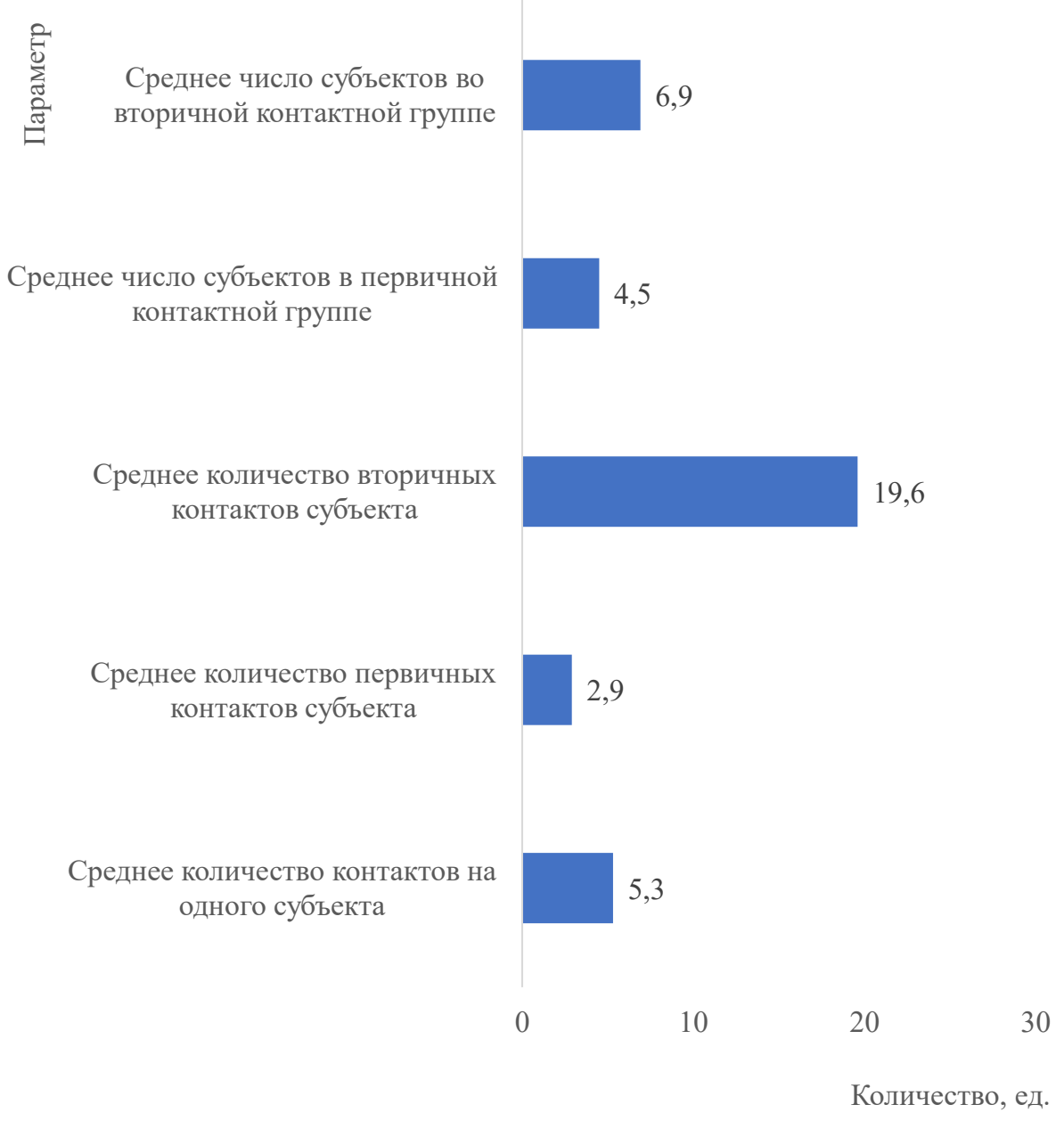

Puc. 1. Некоторые количественные параметры взаимодействия субъектов в обозначенных сферах человеческой деятельности в 2019 году в Российской Федерации (усредненные данные)

дистанцирования, к сожалению, нашел эффективное применение (средний уровень эффективности применения составляет 85 процентов и более) лишь в 62,89 процентах субъектов. В остальных же высших учебных заведениях Российской Федерации уровень эффективности применения института социального дистанцирования находится на недостаточно высоком уровне.

Несмотря на свою эффективность применяемый институт негативным образом влияет на многие параметры функционирования субъектов рынка. Так, например, в высших учебных заведениях Российской Федерации применение дистанционного обучения в 2020 году (второй и третий кварталы) негативным образом отразилось на уровне их инновационной деятельности $[4$, c. 89] в целом и подразделений в частности.

В таблице 1 приведены данные по оценке средних уровней инновационной деятельности высших учебных заведений [2, 3] в Российской Федерации в 2019-2020 годах с поквартальной разбивкой во взаимосвязи с внедрением дистанционного обучения.

Приведенные данные свидетельствую о том, что внедренное дистанционное обучение $[1$, с. 43] существенно повлияло на средний уровень инновационной деятельности высших учебных заведений Российской Федерации в 2020 году. В частности, средний уровень анализируемого показателя за 2019 год составил 65 процентов против 37,2 процентов для 2020 года (с учетом прогнозных данных за 4 квартал). При этом пик снижения здесь приходился на 2 квартал.

Рассматривая ситуацию с оценкой инновационной деятельности в проекции подразделений высших учебных заведений Российской Федерации в 2020 году с поквартальной разбивкой, складывается следующая картина, отраженная в таблице 2. 
Таблица 1. Данные по оценке средних уровней инновационной деятельности высших учебных заведений в Российской Федерации в 2019-2020 годах с поквартальной разбивкой

\begin{tabular}{|c|c|c|c|c|}
\hline Период & \multicolumn{2}{|c|}{$\begin{array}{c}\text { Тип данных и их оценка } \\
\text { (исходные и с учетом корректировки на } \\
\text { подход к их оценке) }\end{array}$} & $\begin{array}{l}\text { Средний уровень } \\
\text { инновационной де- } \\
\text { ятельности высших } \\
\text { учебных заведений, }\end{array}$ & $\begin{array}{c}\text { Влияние дистанци- } \\
\text { онного обучения } \\
\text { (0-10), ед. }\end{array}$ \\
\hline \multirow{2}{*}{$\begin{array}{l}1 \text { квартал } \\
2019 \text { года }\end{array}$} & \multirow{2}{*}{ Фактические } & Исход & 64,1 & - \\
\hline & & Корректировка & 65,9 & - \\
\hline \multirow{2}{*}{$\begin{array}{l}2 \text { квартал } \\
2019 \text { года }\end{array}$} & \multirow{2}{*}{ Фактические } & Исход & 63,5 & - \\
\hline & & Корректировка & 63,8 & - \\
\hline \multirow{2}{*}{$\begin{array}{l}3 \text { квартал } \\
2019 \text { года }\end{array}$} & \multirow{2}{*}{ Фактические } & Исход & 64,5 & - \\
\hline & & Корректировка & 64,2 & - \\
\hline \multirow{2}{*}{$\begin{array}{l}4 \text { квартал } \\
2019 \text { года }\end{array}$} & \multirow{2}{*}{ Фактические } & Исход & 67,8 & - \\
\hline & & Корректировка & 66,1 & - \\
\hline \multirow{2}{*}{$\begin{array}{l}1 \text { квартал } \\
2020 \text { года }\end{array}$} & \multirow{2}{*}{ Фактические } & Исход & 65,0 & - \\
\hline & & Корректировка & 63,9 & 1 \\
\hline \multirow{2}{*}{$\begin{array}{l}2 \text { квартал } \\
2020 \text { года }\end{array}$} & \multirow{2}{*}{ Фактические } & Исход & 24,9 & - \\
\hline & & Корректировка & 23,8 & 9 \\
\hline \multirow{2}{*}{$\begin{array}{l}3 \text { квартал } \\
2020 \text { года }\end{array}$} & \multirow{2}{*}{ Фактические } & Исход & 30,8 & - \\
\hline & & Корректировка & 31,4 & 7 \\
\hline \multirow{2}{*}{$\begin{array}{l}4 \text { квартал } \\
2020 \text { года }\end{array}$} & \multirow{2}{*}{ Прогнозные } & Исход & 30,2 & - \\
\hline & & Корректировка & 29,7 & 8 \\
\hline
\end{tabular}

Таблица 2. Ситуация с оценкой инновационной деятельности в проекции подразделений высших учебных заведений Российской Федерации в 2020 году с поквартальной разбивкой

\begin{tabular}{|c|c|c|}
\hline Период & $\begin{array}{c}\text { Тип распределения оцененного } \\
\text { уровня инновационной деятельно- } \\
\text { сти по подразделениям }\end{array}$ & $\begin{array}{c}\text { Значение распределения оце- } \\
\text { ненного уровня инновационной } \\
\text { деятельности по подразделениям }\end{array}$ \\
\hline \multirow{2}{*}{$\begin{array}{l}1 \text { квартал } \\
2019 \text { года }\end{array}$} & количественное (0-100),\% & 90,85 \\
\hline & качественное & полный охват \\
\hline \multirow{2}{*}{$\begin{array}{l}2 \text { квартал } \\
2019 \text { года }\end{array}$} & количественное (0-100),\% & 89,36 \\
\hline & качественное & полный охват \\
\hline \multirow{2}{*}{$\begin{array}{l}3 \text { квартал } \\
2019 \text { года }\end{array}$} & количественное (0-100),\% & 87,38 \\
\hline & качественное & полный охват \\
\hline \multirow{2}{*}{$\begin{array}{l}4 \text { квартал } \\
2019 \text { года }\end{array}$} & количественное (0-100),\% & 95,44 \\
\hline & качественное & полный охват \\
\hline \multirow{2}{*}{$\begin{array}{l}1 \text { квартал } \\
2020 \text { года }\end{array}$} & количественное (0-100),\% & 89,45 \\
\hline & качественное & частичный охват \\
\hline \multirow{2}{*}{$\begin{array}{l}2 \text { квартал } \\
2020 \text { года }\end{array}$} & количественное (0-100),\% & 49,89 \\
\hline & качественное & частичный охват \\
\hline \multirow{2}{*}{$\begin{array}{l}3 \text { квартал } \\
2020 \text { года }\end{array}$} & количественное (0-100),\% & 50,36 \\
\hline & качественное & частичный охват \\
\hline \multirow{2}{*}{$\begin{array}{l}4 \text { квартал } \\
2020 \text { года }\end{array}$} & количественное (0-100),\% & 51,85 \\
\hline & качественное & частичный охват \\
\hline
\end{tabular}


Как видно из таблицы 2, с начала мировой пандемии (конец 1 квартала 2020 года) значения распределения оцененного уровня инновационной деятельности по подразделениям высших учебных заведений в российской Федерации стали снижаться как в количественном, так и качественном аспектах. То есть все меньшее количество подразделений стало вовлечено в сам процесс инновационной деятельности, как таковой.

Для разрешения сложившейся ситуации, на наш взгляд, необходимо реализовать следующий комплекс мер:

- адаптировать процесс оценки уровня инновационной деятельности подразделений высших учебных заведений исходя из специфики сложившейся ситуации (здесь целесообразно скорректировать не саму методологию, а лишь методику, например, за счет включения ряда новых специфически значимых факторов);

- модернизировать интерпретацию результатов оценки уровня инновационной деятельности подразделений высших учебных заведений, полагаясь, в первую очередь, на их ориентированность и специфику деятельности (это может быть, например, фактор масштаба, количества необходимого персонала, уровня материальной базы и прочее);

- на комплексной основе мотивировать персонал подразделений высших учебных заведений, переведенный на удаленный формат работы (дистанционное обучение) к участию в процессе инновационной деятельности и получению формальных и экономически значимых результатов (например, можно делегировать подразделениям высших учебных заведений наименее задействованным в процессе иннова- ционной деятельности часть работ, исходя из их профиля и наличия фактических ресурсов).

Таким образом, можно сделать вывод, что в условиях мирового кризиса, вызванного пандемией коронавирусной инфекции, многие высшие учебные заведения в Российской Федерации с конца первого квартала 2020 года стали активнее применять институт дистанционного обучения.

Одним из результатов данного действия стало снижение ряда важнейших показателей функционирования высших учебных заведений, связанных в том числе, с их инновационной деятельностью. В частности, за второй и третий кварталы в 2020 году в Российской Федерации значительно снизился уровень их инновационной деятельности. Некоторые сложности здесь также имели место при проведении процедуры оценки и интерпретации полученных результатов.

Для решения обозначенных проблем целесообразно, на наш взгляд: адаптировать процесс оценки уровня инновационной деятельности подразделений высших учебных заведений исходя из специфики сложившейся ситуации; модернизировать интерпретацию результатов оценки уровня инновационной деятельности подразделений высших учебных заведений, ориентируясь, в первую очередь, на их ориентированность и специфику деятельности; на комплексной основе мотивировать персонал подразделений высших учебных заведений, переведенный на удаленный формат работы (дистанционное обучение) к участию в процессе инновационной деятельности и получению формальных и экономически значимых результатов.

\section{Библиографический список}

1. Романова М. Н., ФилипповаС.Ф. Дистанционное обучение студентов очного обучения / М.Н.Романова, С.Ф.Филиппова // Современное образование: традиции и инновации - Санкт-Петербург: Изд-во ООО «ООО «НИЦ АРТ», 2020.- № 3.- С. 41-44.

2. Фраймович Д.Ю. Проектирование деятельности опорного вуза как инновационного центра региона / Д. Ю. Фраймович // Экономические науки - М: Изд-во: «ООО «24 Принт», 2019. - № 11.- С. 87-90.

3. Франк E. B. Современная проблематика в построении системы управления инновациями в опорных вузах регионов / Е. В. Франк // Экономические науки - М: Изд-во: «ООО «24 Принт», 2019. - № 3. - С. $76-80$.

4. Ходжи E. В. Методические подходы к оценке результативности и эффективности инновационной деятельности высшего учебного заведения / Е. В. Ходжич // Экономика: вчера, сегодня, завтра - Москва: Изд-во: «Аналитика Родис», 2019.- № 10-1.- С. 88-98.

5. Шатуновский В. Л., Шатуновская Е. А. Ещё раз о дистанционном обучении (организация и обеспечение дистанционного обучения) / В. Л. Шатуновский, Е.А. Шатуновская // Вестник науки и образования - Иваново: Изд-во: «Олимп», 2020.- № 9-1.-С. 53-56. 
6. Компания «Эксперт РА» [Электронный ресурс]: аналитические материалы - Официальный сайт компании «Эксперт РА», 2020.- Режим доступа: www.raexpert.ru

7. Компания «Ernst\&Young» [Электронный ресурс]: аналитические материалы - Официальный сайт компании «Ernst\&Young», 2020.- Режим доступа: https://www.ey.com/ru_ru 